\title{
Epidemiologic and viral predictors of antiretroviral drug resistance among persons living with HIV in a large treatment program in Nigeria
}

Ernest Ekong ${ }^{1,2^{*}+\wedge}$, Nicaise Ndembi ${ }^{1,2^{*}+}$ (1) , Prosper Okonkwo ${ }^{3}$, Patrick Dakum ${ }^{1,2}$, John Idoko ${ }^{4}$, Bolanle Banigbe ${ }^{3}$, James Okuma ${ }^{1}$, Patricia Agaba ${ }^{4}$, William Blattner ${ }^{2}$, Clement Adebamowo ${ }^{2}$ and Manhattan Charurat $^{2}$

\begin{abstract}
Background: Expanded access to combination antiretroviral therapy (CART) throughout sub-Saharan Africa over the last decade has remarkably improved the prognosis of persons living with HIV (PLWH). However, some PLWH experience virologic rebound after a period of viral suppression, usually followed by selection of drug resistant virus. Determining factors associated with drug resistance can inform patient management and healthcare policies, particularly in resource-limited settings where drug resistance testing is not routine.

Methods: A case-control study was conducted using data captured from an electronic medical record in a large treatment program in Nigeria. Cases PLWH receiving CART who developed acquired drug resistance (ADR) and controls were those without ADR between 2004 and 2011. Each case was matched to up to 2 controls by sex, age, and education. Logistic regression was used estimate odds ratios (ORs) and 95\% confidence intervals (Cls) for factors associated with ADR.

Results: We evaluated 159 cases with ADR and 299 controls without ADR. In a multivariate model, factors associated with $A D R$ included older age $(\mathrm{OR}=2.35$ [age $30-40$ years $95 \% \mathrm{Cl} 1.29,4.27$ ], age $41+$ years $\mathrm{OR}=2.31$ [95\% Cl 1.11, 4.84], compared to age 17-30), higher education level (secondary OR 2.14 [95\% Cl 1.1.11-4.13]), compared to primary and tertiary), non-adherence to care $(\mathrm{OR}=2.48[95 \% \mathrm{Cl} 1.50-4.00])$, longer treatment duration $(\mathrm{OR}=1.80[95 \% \mathrm{Cl}$ 1.37-2.35]), lower $C D 4$ count $((\mathrm{OR}=0.95$ [95\% Cl 0.95-0.97]) and higher viral load $(\mathrm{OR}=1.97$ [95\% Cl 1.44-2.54]).
\end{abstract}

Conclusions: Understanding these predictors may guide programs in developing interventions to identify patients at risk of developing ADR and implementing prevention strategies.

Keywords: Antiretroviral therapy, Acquired drug resistance, Predictors, HIV drug resistance testing, Low Middle Income Countries (LMICs), Resource-limited settings

*Correspondence: ernestekong@ihvnigeria.org; nndembi@ihvnigeria.org tErnest Ekong and Nicaise Ndembi contributed equally to this work Ernest Ekong-Deceased

1 Department of Prevention, Care and Treatment, Institute of Human Virology-Nigeria (IHVN), Federal Capital Territory, Plot 252, Herbert Macaulay Way, Central Business District, Abuja, Nigeria

Full list of author information is available at the end of the article

\section{Introduction}

Acquired and transmitted antiretroviral drug resistance mutations among persons living with HIV (PLWH) are a major public health concern, as they can limit the efficacy of available drugs for the management of HIV [1]. Resistance to antiretroviral (ARV) agents and subsequently increasing levels of transmitted, resistant virus have been identified by many researchers to potentially reverse the

c) The Author(s) 2020. This article is licensed under a Creative Commons Attribution 4.0 International License, which permits use, sharing, adaptation, distribution and reproduction in any medium or format, as long as you give appropriate credit to the original author(s) and the source, provide a link to the Creative Commons licence, and indicate if changes were made. The images or other third party material in this article are included in the article's Creative Commons licence, unless indicated otherwise in a credit line to the material. If material is not included in the article's Creative Commons licence and your intended use is not permitted by statutory regulation or exceeds the permitted use, you will need to obtain permission directly from the copyright holder. To view a copy of this licence, visit http://creativeco mmons.org/licenses/by/4.0/. The Creative Commons Public Domain Dedication waiver (http://creativecommons.org/publicdomain/ zero/1.0/) applies to the data made available in this article, unless otherwise stated in a credit line to the data. 
substantial gains achieved with potent ART [2-4]. Both transmitted drug resistance (TDR) and acquired drug resistance (ADR) reflect the relative usage of different ARV drugs in the population and the inherent genetic barrier to the development of resistance associated with individual drugs.

Development of drug resistance in chronic HIV infection has serious implications $[5,6]$. Apart from the resultant limitations in the choice of effective treatment regimens, there are also extra cost implications associated with switches to second or third line therapy and extra demands on laboratory monitoring of patients [79]. Transmitted or pretreatment HIV drug resistance has significant impact on effectiveness of antiretroviral therapy. It leads to limitations in choice of effective regimen, longer time to achieve viral suppression and shorter time to virologic failure as compared to infection with a viral strain that is not drug resistant [10-12]. Even though several studies have shown that ADR is an independent predictor of virologic failure in naïve and treated HIV patients, factors that predict ADR are still not properly documented. Several studies suggest a $6 \%$ to $16 \%$ prevalence of HIV drug resistance in ART-naive patients [12, 13]. Virologic success has been shown to be predicted by high potency of ARV regimen, excellent adherence to treatment regimen [14], low viremia at ART initiation, higher CD4 count at ART initiation $\left(>200\right.$ cells $\left./ \mathrm{mm}^{3}\right)$ [15] and rapid reduction of viremia in response to treatment [16].

It is important to understand the interplay of factors associated with HIV drug resistance, especially in low to middle-income countries (LMICs) where there is limited access to viral load testing [17]. In this study we used data collected from the AIDS Prevention Initiative in Nigeria (APIN) program, a comprehensive HIV care and treatment program in the country, to evaluate sociodemographic, socioeconomic and other factors that could be associated or predict ADR in Nigeria.

\section{Materials and methods}

\section{Study setting and study design}

Since 2004, the AIDS Prevention Initiative in Nigeria (APIN) has provided care and treatment to more than 200,000 HIV/AIDS patients in several Nigerian cities, including: Lagos (Southwest zone, Lagos state), Jos (Northcentral zone, Plateau state), Ibadan (Southwest zone, Oyo state), and Maiduguri (Northeast zone, Borno state). This was a retrospective multi-centre case-control study of participants failing first-line ART at five Nigerian ART centers providing treatment and care (University College Hospital, Ibadan; National Institute for Medical Research, Lagos; Jos University
Teaching Hospital, Jos; University of Maiduguri Teaching Hospital; and AIDS Prevention Initiative in Nigeria (APIN)). First-line treatment consisted of two nucleoside reverse transcriptase inhibitors (NRTIs), most commonly stavudine (d4T), zidovudine (AZT), or tenofovir (TDF), plus lamivudine (3CT) or emtricitabine (FTC) and one nonnucleoside reverse transcriptase inhibitor (NNRTI) such as nevirapine (NVP) or efavirenz (EFV). During the study period (2004-2011) we had three different WHO guidelines in 2003, 2006 and 2010 [18-20]. The study population included PLWH aged 18 years and above with at least two documented clinic visits during the study period of June 2004 through 31 December 2011. Initiation of first-line ART as defined by the national guidelines of the period included advanced immunodeficiency as defined by CD4 count, or advanced disease according to the World Health Organization (WHO) clinical stages. Patients with documented evidence of drug resistance (from genotypic drug resistance tests) between 2004 and 2011 from selected APIN sites were defined as cases, while those that had no evidence of antiretroviral drug resistance were the controls. Patients who did not start ART or require HIV therapy based on national treatment guidelines in effect at the time, patients without time of ART initiation electronic medical records, patients who made only a one-time HIV consultation visit, or those with less than 12 months of follow-up data, were excluded from the study.

\section{Data collection procedure and data collectors}

The APIN electronic medical record system has been used in Nigeria since 2004. The system allows for longitudinal follow-up for all patients accessing care at the various treatment centers. Patients are given unique patient identifier numbers and tracked from program inception and during their follow-up visits. Patients' demographic and clinical data routinely collected at outpatient counters, inpatient services, laboratory, voluntary HIV counseling and testing, and ART clinic and pharmacy, are linked for more efficient analysis of the prevention, care, and support program. Both case and control participants were initially identified from the dataset. Baseline demographic data at the time of ART initiation were recorded including sex, age, education, and occupation. Clinical data included CD4 cell count, HIV RNA level, TB and hepatitis status, date ART was commenced, current and past ART regimens, transfer of HIV care, resistance/mutations results, history of ARV experience, and the drug pickups, viral loads, and ARV drug history, were manually extracted from the individual patient's case notes. 


\section{Definitions}

Measurement or determination of drug adherence was not standardized at the sites, with some using the pillcount, some pharmacy refill data, while others relied on self-report. In the pill count method, the unused pills were recorded for each patient on their subsequent clinic visit. The number of unused pills for the entire period of follow-up was obtained by totaling the pills unused in each month (cumulative unused pills). Where this information was available, adherence rate (\%) was calculated as total doses taken as a percentage of total doses prescribed. CD4 cell count was measured every month during the first year and once every 3 months thereafter.

Treatment failure was categorized as virologic, immunologic or clinical. The definition of virologic failure evolved over time from two consecutive HIV ribonucleic acid (RNA) $>400$ copies/ml after 24 weeks or $>50$ copies/ $\mathrm{ml}$ by 48 weeks in a treatment-naive patient or virological rebound (where there was a confirmed HIV-1 RNA $>50$ copies/ml after initial virological suppression). Immunologic failure was defined as failure to achieve and maintain CD4 cell count $>350$ cells $/ \mathrm{mm}^{3}$ despite virological suppression (HIV-1 RNA $<50$ copies/ml) after $\geq 2$ years of antiretroviral treatment. For the purposes of this study, the WHO immunologic criteria for treatment failure used were a decline in the CD4 cell count to the value at ART initiation or below, a decline of at least $50 \%$ from the highest count on treatment or a persistent CD4 cell count below 100 cells/l after 6 months of ART [21]. Virologic failure was defined as a viral load of 1000 copies/ $\mathrm{ml}$ (higher threshold) or as a viral load of 500 copies $/ \mathrm{ml}$ (lower threshold) [21].

In clinical failure, there would have been the occurrence or recurrence of HIV-related events after at least 3 months of ART initiation, excluding immune reconstitution syndromes. At the beginning of program implementation, the most common first-line ART included stavudine (d4T), lamivudine (3TC), and nevirapine (NVP). In late 2006, the increased recognition of the toxicity and inferior efficacy of regimens containing $\mathrm{d} 4 \mathrm{~T}$ prompted the revision of international guidelines, with eventual removal of $\mathrm{d} 4 \mathrm{~T}$ from recommended first-line regimens. In 2008-2009, the introduction of generic tenofovir (TDF) equivalents and the fixed-dose combination (FDC) with emtricitabine (FTC) and efavirenz (EFV) further expanded usage of TDF in lieu of $d 4$ [22].

\section{Statistical analysis}

Using a test of proportion for difference between cases and controls ( $3 \%$ vs $13 \%$ ), a two-sided type I error of 0.05 , and power of 0.95 , a minimum of 305 patients without ARV resistance and 153 patients with documented evidence of ARV resistance was required for the analysis. All statistical analyses were carried out using STATA version 11.0 (College Station, TX, USA) [23]. The total number of participants was 458 (299 without ADR and 159 with ADR).

We used mean and standard deviation (SD) to summarize continuous variables and proportions for categorical variables to describe basic characteristics of the study population. We tested for differences between cases and controls using the Chi square test for categorical variables and Wilcoxon Rank-sum test for continuous variables with $\mathrm{p}<0.05$ considered statistically significant. Logistic regression models were used to estimate Odd Ratios (OR) and 95\% confidence intervals (CI). Univariate models were first run with ADR as the dependent variable and each of the predictors as independent variables. Factors that were associated with developing ADR at a $\mathrm{p}$-value $\leq 0.20$ in univariate models were further examined in multivariate models, with adjustment for a range of factors which included socio-demographic, clinical and immunologic characteristics, time of study enrolment and duration on ART. Final model includedpotential confounders as well as established risk factors for developing ADR. Statistical analyses was conducted using SAS version 11.0 (SAS Institute, Cary, NC) statistical software.

\section{Results}

A total of 458 study participants comprised of 299 (65.3\%) HIV-infected individuals failing ART without ADR and 159 (34.7\%) HIV-infected individuals failing ART with ADR were included in the analysis. The baseline (time to ART initiation) characteristics of the study participants is shown in Table 1. ARVDR+and ARVDRwere significantly different by the proportion of married individuals $(52.9 \%$ vs. $47.1 \%, \mathrm{p}<0.001)$, occupation $(60 \%$ vs. $53 \%, \mathrm{p}=0.038$ ), and education status (Secondary and Tertiary, $73 \%$ vs. $56 \%, \mathrm{p}=0.002$ ). Mean duration on treatment was 3.5 years $(\mathrm{SD}=1.3)$ for the ARVDR+ and 2.6 years $(S D=1.1)$ for the ARVDR $-(\mathrm{p}<0.001)$. Mean $\mathrm{CD} 4$ count at $\mathrm{ADR}$ was 390 cells $/ \mu \mathrm{l}(\mathrm{SD}=111$ cells/ $\mu \mathrm{l})$ for ARVDR - and 170 cells $/ \mu \mathrm{l}(\mathrm{SD}=72 \mathrm{cells} / \mu \mathrm{l})$ for ARVDR+ $(\mathrm{p}<0.001)$. Non-adherence to ART was higher among the ARVDR+than the ARVDR-, $60 \%$ vs $29 \%$, $\mathrm{p}<0.001$. There were no significant differences among ARVDR+ and ARVDR - for age, gender, baseline CD4 count and previous ART regimens (Table 1).

In bivariate model, education (secondary and tertiary), year of enrolment, non-adherence, Hepatitis $B$ status, treatment duration and baseline viral load were associated with the development of ADR. However, in a multivariate model, after adjusting for potential confounding variables, older age (age group 31-40 
Table 1 Baseline characteristics of study participants

\begin{tabular}{|c|c|c|c|c|}
\hline Patient characteristics & $\begin{array}{l}\text { All patients } \\
n=458\end{array}$ & $\begin{array}{l}\text { Without ADR } \\
N=299\end{array}$ & $\begin{array}{l}\text { With ADR } \\
N=159\end{array}$ & P-value \\
\hline \multicolumn{5}{|l|}{ Socio-demographics } \\
\hline Age (years), mean (SD) & $34.7(9.0)$ & $34.3(9.0)$ & $35.5(9.0)$ & 0.08 \\
\hline \multicolumn{5}{|l|}{ Age categories (years) (\%) } \\
\hline $17-30$ & $163(35.6 \%)$ & $116(38.8 \%)$ & $47(29.6 \%)$ & 0.15 \\
\hline $31-40$ & $181(39.5 \%)$ & $112(37.5 \%)$ & $69(43.4 \%)$ & \\
\hline 41 and above & $114(25.9 \%)$ & $71(23.8 \%)$ & $43(27.0 \%)$ & \\
\hline Gender, female (\%) & $298(65.1 \%)$ & 200 (66.9\%) & $98(61.6 \%)$ & 0.26 \\
\hline Married status, married (\%) & $239(52.9 \%)$ & $177(60.4 \%)$ & $62(39.0 \%)$ & $<0.001$ \\
\hline \multicolumn{5}{|l|}{ Occupation (\%) } \\
\hline Unemployed & $204(44.5 \%)$ & $141(47.2 \%)$ & $63(39.6 \%)$ & 0.038 \\
\hline Employed & $254(55.4 \%)$ & $158(52.8 \%)$ & $96(60.3 \%)$ & \\
\hline \multicolumn{5}{|l|}{ Education (\%) } \\
\hline None & $108(23.6 \%)$ & $80(26.8 \%)$ & $28(17.6 \%)$ & 0.002 \\
\hline Primary & $67(14.6 \%)$ & $53(17.7 \%)$ & $14(8.8 \%)$ & \\
\hline Secondary & $158(34.5 \%)$ & $93(31.1 \%)$ & $65(40.9 \%)$ & \\
\hline Tertiary & $125(27.3 \%)$ & $73(24.4 \%)$ & $52(32.7 \%)$ & \\
\hline \multicolumn{5}{|l|}{ Clinical } \\
\hline \multicolumn{5}{|l|}{ Year of enrolment (\%) } \\
\hline 2004-2006 & $222(58.9 \%)$ & 125 (48.5\%) & $97(80.2 \%)$ & $<0.001$ \\
\hline 2007-2011 & $157(41.4 \%)$ & $133(51.6 \%)$ & $24(19.8 \%)$ & \\
\hline ART treatment duration (years), mean (SD) & $2.9(1.2)$ & $2.6(1.1)$ & $3.5(1.3)$ & $<0.001$ \\
\hline Baseline CD4 count (cells/ $\mu \mathrm{l})$, mean (SD) & $160(88)$ & $161(91)$ & $159(81)$ & 0.98 \\
\hline 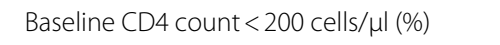 & $277(61.8 \%)$ & $188(62.9 \%)$ & $89(59.7 \%)$ & 0.52 \\
\hline 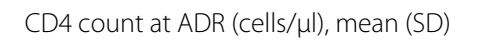 & $317(144)$ & $390(111)$ & $170(72)$ & $<0.001$ \\
\hline CD4 count at ADR < 200 cells/ $\mu$ l (\%) & $109(24.3 \%)$ & $7(2.3 \%)$ & $102(68.5 \%)$ & $<0.001$ \\
\hline Baseline viral load log 10, mean (SD) & $4.46(1.00)$ & $4.24(1.02)$ & $4.87(0.84)$ & $<0.001$ \\
\hline \multicolumn{5}{|l|}{ Previous ARV regimen (\%) } \\
\hline NNRTI & $422(92.1 \%)$ & $278(93.0 \%)$ & $144(90.6 \%)$ & 0.36 \\
\hline $\mathrm{Pl}$ & $36(7.9 \%)$ & $21(7.0 \%)$ & $15(9.4 \%)$ & \\
\hline Non-adherence to care (\%) & $183(40.0 \%)$ & $87(29.1 \%)$ & $96(60.4 \%)$ & $<0.001$ \\
\hline Hepatitis B status (\%) & $97(20.2 \%)$ & $59(19.7 \%)$ & $38(23.9 \%)$ & 0.30 \\
\hline
\end{tabular}

NNRTI non-nucleoside reverse transcriptase inhibitors, PI protease inhibitors, ADR adverse drug reaction, ART ARV therapy, ARV antiretroviral

a $\mathrm{P}$-values from Chi squared-test for categorical variables or Wilcoxon test for continuous variables

$(\mathrm{OR}=2.35$ [95\% CI 1.29, 4.27], age group $41+\mathrm{OR}=2.31$ [95\% CI 1.11, 4.84])), being unmarried (single) $(\mathrm{OR}=0.40$ [95\% CI 0.24-0.67]), higher education level (secondary OR 2.14 [95\% CI 1.1.11-4.13]; non-adherence to care $(\mathrm{OR}=2.48$ [95\% CI 1.50-4.00]), longer treatment duration $(\mathrm{OR}=1.80$ [95\% CI 1.37-2.35]), and higher viral load $(\mathrm{OR}=1.97$ [95\% CI 1.44-2.54]) remained significantly associated with ADR (Table 2). Although the mean treatment duration overall was 2.9 years $(\mathrm{SD}=1.2)$, those in the case group were longer on treatment (3.5 years, $\mathrm{SD}=1.3)$ than those in the ARVDR - group (2.6 years, $\mathrm{SD}=1.1)$. The study showed that for each year of treatment duration, the odds of developing ARVDR was higher $(\mathrm{OR}=1.80,95 \% \mathrm{CI} 1.37$ to $2.35, \mathrm{p}<0.001)$.

\section{Discussion}

In this study we have shown that older age, being unmarried, duration of treatment $>2$ years, nonadherence, low baseline CD4 count and high baseline VL seem to be associated with (predict of) ADR. These findings somewhat confirm, and at times diverge, from what has been described previously as factors associated with ADR. Although Khienprasit et al. [24] reported in a multivariate analysis that age $<40$ years was predictive of ART failure, oOur findings indicate that older age PLWH are more likely to fail ART and switch to second line regimen, than younger patients. Our findings are in concordance with a large study conducted to assess the influence of age on immune 
Table 2 Univariate and multivariate analyses of predictors of ADR

\begin{tabular}{|c|c|c|c|}
\hline & $\begin{array}{l}\text { \%ADR } \\
\mathrm{n}(\%)\end{array}$ & $\begin{array}{l}\text { Univariate } \\
\text { OR }(95 \% \mathrm{Cl}) \text {, P-value }\end{array}$ & $\begin{array}{l}\text { Multivariate } \\
\text { OR ( } 95 \% \mathrm{CI}) \text {, P-value }\end{array}$ \\
\hline \multicolumn{4}{|l|}{ Age } \\
\hline $17-30$ & $47(29.6 \%)$ & Reference & Reference \\
\hline $31-40$ & 69 (43.4\%) & 1.52 (0.97-2.39), 0.07 & $2.35(1.29-4.27), 0.005$ \\
\hline $41+$ & $43(27.0 \%)$ & $1.50(0.90-2.49), 0.12$ & $2.31(1.11-4.84), 0.026$ \\
\hline \multicolumn{4}{|l|}{ Gender } \\
\hline Female & $98(61.6 \%)$ & Reference & Reference \\
\hline Male & $61(38.4 \%)$ & $1.26(0.84-1.88), 0.26$ & $0.73(0.42-1.29), 0.28$ \\
\hline \multicolumn{4}{|l|}{ Marital status } \\
\hline Single & $97(61.0 \%)$ & Reference & Reference \\
\hline Married & $62(39.0 \%)$ & $0.42(0.28,0.62),<0.001$ & $0.40(0.24,0.67),<0.001$ \\
\hline \multicolumn{4}{|l|}{ Occupation } \\
\hline Un-employed & $63(39.6 \%)$ & Reference & Reference \\
\hline Employed & $96(60.4 \%)$ & $1.36(0.92-2.01), 0.12$ & $1.17(0.68-2.02), 0.56$ \\
\hline \multicolumn{4}{|l|}{ Education } \\
\hline None & $28(17.6 \%)$ & Reference & Reference \\
\hline Primary & $14(8.8 \%)$ & $0.76(0.36-1.57), 0.45$ & $0.61(0.26-1.45), 0.26$ \\
\hline Secondary & $65(40.9 \%)$ & $2.00(1.57-3.41), 0.011$ & $2.14(1.11-4.13), 0.02$ \\
\hline Tertiary & $52(32.7 \%)$ & $2.04(1.17-3.56), 0.013$ & $1.41(0.69-2.85), 0.35$ \\
\hline \multicolumn{4}{|l|}{ Year of enrolment } \\
\hline 2004-2006 & $97(80.2 \%)$ & $2.83(1.88-4.26),<0.001$ & $1.11(0.58-2.11), 0.76$ \\
\hline 2007-2011 & $24(19.8 \%)$ & Reference & Reference \\
\hline Enrolment year & & $0.51(0.43-0.61),<0.001$ & \\
\hline \multicolumn{4}{|l|}{ Previous ARV regimen } \\
\hline NNRTI & $144(90.6 \%)$ & $0.73(0.36-1.45), 0.36$ & \\
\hline $\mathrm{Pl}$ & $15(9.4 \%)$ & Reference & \\
\hline \multicolumn{4}{|l|}{ Non-adherence } \\
\hline No & $63(40.0 \%)$ & Reference & Reference \\
\hline Yes & $96(60.4 \%)$ & $3.71(2.48-5.56),<0.001$ & $2.48(1.50-4.00),<0.001$ \\
\hline \multicolumn{4}{|l|}{ Hepatitis B status } \\
\hline No & $121(76.0 \%)$ & Reference & \\
\hline Yes & $38(23.9 \%)$ & $1.28(0.80-2.03), 0.30$ & \\
\hline Treatment duration (years) & & $1.93(1.61-2.31),<0.001$ & $1.80(1.37-2.35),<0.001$ \\
\hline \multicolumn{4}{|l|}{ Baseline CD4 count } \\
\hline $200+$ & $60(40.3 \%)$ & Reference & \\
\hline$<200$ & $89(59.7 \%)$ & $0.88(0.59-1.31), 0.52$ & \\
\hline \multicolumn{4}{|l|}{ CD4 count at ADR } \\
\hline $200+$ & $47(13.5 \%)$ & Reference & Reference \\
\hline$<200$ & $102(68.5 \%)$ & $0.97(0.96-0.98),<0.001$ & $0.95(0.94-0.97),<0.001$ \\
\hline Baseline viral load at ADR (log10) & & $2.08(1.65-2.64),<0.001$ & $1.97(1.44-2.54),<0.001$ \\
\hline
\end{tabular}

NNRTI non-nucleoside reverse transcriptase inhibitors, PI protease inhibitors, $A D R$ adverse drug reaction, $A R T$ ARV therapy, $A R V$ antiretroviral

a $\mathrm{P}$-values from Chi squared-test for categorical variables or Wilcoxon test for continuous variables

recovery [25]. This effect of age on immune recovery with subsequent switch seems to be due to reduced thymic function that could impair immune recovery $[26,27]$. Another reason for older patients to be more prone to ADR may be due to delayed diagnosis in this age group as HIV-associated symptoms can be mistaken for other diseases or even aging [28]. Older HIV patients are more susceptible to faster progression of the disease, with shorter and less symptomatic stage [28]. The use of other medications for concomitant co-morbidities among older patients may result in drug-drug interaction which predisposes to ADR and 
also predisposes to greater risk of opportunistic infections [29]. However, aging is generally expected to be a marker for greater maturity, lifestyle stability, and disease-specific education capable of affecting long-term adherence to therapy [30].

Married people usually have more family support so adherence to ART can be better handled or prevented through being reminded by the spouse or other family members. Marital status has been found to influence health and mortality, and give a lot of stability. KiecoltGlaser and Wilson [31] in their report on intimate partner relationships and health recorded that married people have significantly better health and a lower mortality than their single counterparts. Regarding HIV infection, social support has been linked to make for better adjustment [32], better treatment adherence [33, 34], and slower progression to AIDS [35, 36]. Molloy et al. [37] identified the presence of a primary partner as a key predictor of maintaining good health.

Another major predictor of ADR was education. However, when adjusted for confounders, only secondary education remained statistically significant. Two different studies, one in Southeast Nigeria, and another in Upper West Region of Ghana [38, 39] reported a negative association between education and adherence. The main reasons for this association could be the psychological state of the more educated person from stigmatization resulting in poor ART adherence. However, Rachlis et al. [40] have shown in a systematic review of studies in LMICs that higher education was associated with good adherence. A lower level of general education and poorer literacy may impact negatively on some patients' ability to adhere, while a higher level of education has a positive impact [41].

The mean treatment duration was significantly different between those that developed ADR and those that did not. This result is not surprising. In the early part of the ART program in Nigeria there were months of drug stock-outs, lack of adequate supply management of medical commodities, weak laboratory infrastructure, and conditions that may favor the occurrence of high levels of ADR. Monitoring of treatment was only done by CD4 cell count and hardly viral load and genotype testing. Patients would therefore have been maintained on virologically failing regimens while multidrug resistant viruses accumulated and thereby made available drugs ineffective over time. In a comparable study in Tanzania by Asgeir et al. [42] the emergence of ADR in rural Tanzania was evaluated. Only a few studies have assessed long-term ( $>2$ years) emergence of drug resistance in sub-Saharan Africa. An early study from Senegal showed that $12.5 \%$ had one or more drug resistant mutations after a median of 30 months on ART (Laurent et al. [43]), whereas a study from Côte d'Ivoire found $22 \%$ resistance after a median period of 37 months on ART [44].

Incidentally, baseline CD4 cell count prior to ART initiation regarded as the most significant predictor of survival after initiation of first ART, was not strongly linked to the development of drug resistance. However, the CD4 count at development of ADR was very significant. The association between $\mathrm{CD} 4$ cell count and drug resistance has a biological reason. In this study, however, the analyses may have been partly confounded by the fact that most of the patients were enrolled on treatment with very low CD4 cell counts. Uy et al. [45] and Jose et al. [46] in their studies also separately reported that resistance occurs quite regularly in persons who initiate therapy later (with low $\mathrm{CD} 4$ count) during infection than in those who initiate ART much earlier. Earlier development of resistance may reduce available therapeutic options later [47]. The other significant observation found in this study was high viral load at ART initiation as a predictor of the development of ADRs in the future. This may be partly attributable to incomplete viral suppression in individuals with higher viral loads at ART initiation [48]. Ongoing low-level viremia is an independent risk factor for future viral failure. Another reason is due to the increased presence of drug-resistant minority HIV-1 variants in individuals with high viral load during untreated infection [49]. Nonadherence was shown to have a significant influence on the probability of ARVDR. O'Connor et al. [50] have previously demonstrated how prescription-refill data strongly predict $\mathrm{CD} 4$ cell decline, virologic response, and mortality after initiation of ART. Results from the present study confirm the association between adherence (estimated by prescription-refill percentages) and the development of drug resistance and provide insight into the way in which adherence influences therapy outcome. The results, however, differ from those of Bangsberg et al. [51] who reported that high levels of adherence (as high as $92-100 \%$ ) do not prevent accumulation of drugresistance mutations. In their study, it is likely that their subjects were enrolled in treatment at very high CD4 counts as well as being better prepared in adherence than those of our study. The importance of high adherence to antiretroviral therapy (ART) for HIV disease is well documented, and poor adherence can result in faster disease progression and ADR as well as increased health care costs and sickness., morbidity, mortality, and heightened risk of secondary HIV transmission [52].

The main limitation in this study was that data extracted from routine medical records may have been incomplete, inconclusive, or inaccurate. Additionally, it was difficult to know which factor acted first in the development of ADR in a patient who had several identified predictors. For the purposes of this study an 
association design was appropriate despite its limitations because the intention of this study was to determine if a relationship existed between the predictors and ADR.

The predictors outlined in this study should be recognised among vulnerable populations by health care providers especially in the resource-limited settings. It becomes critical to educate patients of possible onset of ADR especially those who are vulnerable based on these identified predictors. Policy makers, social advocacy groups and Health Ministries would use the information and be more focused in treatment and deploy resources to managing many more patients on firstline drugs instead of few on the much more expensive, scarce, second and third-line drugs due to the development of ADR.

\section{Acknowledgements}

We would like to acknowledge staff of the Nigerian Institute of Medical Research (NIMR) Lagos, University College Hospital (UCH) Ibadan, University of Maiduguri Teaching Hospital (UMTH) Maiduguri, and Jos University Teaching Hospital (JUTH) Jos, study participants and data clerks who assisted us in data entry. This work was supported by the U.S. Centers for Disease Control and Prevention (CDC) Global HIV and TB Program. The content is solely the responsibility of the authors and does not necessary represent the official views of the funders.

\section{Authors' contributions}

Conceived and designed the study, contributed to data collection and manuscript draft and approved the final draft: $E E, N N$. Contributed to the design, statistical estimations and analysis of the data: JO, MC, BB, PA, NN, CA. Contributed to the design, critically reviewed the manuscript for intellectual content and approved the final draft: EE, NN, MC, PD, PO, JI, WB. All authors read and approved the final manuscript.

\section{Funding}

This program evaluation was partly supported by the US National Institute of Health (NIH), NIH R01 Al147331-01.

\section{Availability of data and materials}

The data that support the findings of this study are PEPFAR data available from the APIN Public Health Initiatives Limited (APIN) but restrictions may apply to the availability of these data, which were used under license for the current study, and so are not publicly available. Data are however available from the authors upon reasonable request and with permission of APIN.

\section{Ethics approval and consent to participate}

For this study, a data use agreement was made between the first author and APIN. All necessary precautions were made to ensure patient confidentiality.

\section{Consent for publication}

Not applicable.

\section{Competing interests}

The authors declare that they have no competing interests.

\section{Author details}

${ }^{1}$ Department of Prevention, Care and Treatment, Institute of Human VirologyNigeria (IHVN), Federal Capital Territory, Plot 252, Herbert Macaulay Way, Central Business District, Abuja, Nigeria. ${ }^{2}$ Institute of Human Virology, University of Maryland School of Medicine, Baltimore, MD, USA. ${ }^{3}$ AIDS Prevention Initiative, Abuja, Nigeria. ${ }^{4}$ Jos University Teaching Hospital, Jos, Nigeria.

\section{References}

1. Ssemwanga D, et al. Update on HIV-1 acquired and transmitted drug resistance in Africa. AIDS Rev. 2015;17(1):3-20.

2. Boender TS, Sigaloff KC, MCMahon JH, et al. Long-term virological outcomes of first-line antiretroviral therapy for HIV-1 in low- and middleincome countries: a systematic review and meta-analysis. Clin Infect Dis. 2015;61:1453-61.

3. Hamers RL, Schuurman R, Sigaloff KC, Wallis CL, Kityo C, Siwale M, Mandaliya K, Ive P, Botes ME, Wellington M, Osibogun A, PharmAccess African Studies to Evaluate Resistance (PASER) Investigators. Effect of pretreatment HIV-1 drug resistance on immunological, virological, and drugresistance outcomes of first-line antiretroviral treatment in sub-Saharan Africa: a multicentre cohort study. Lancet Infect Dis. 2012;12(4):307-17.

4. WHO. Global action plan for HIV drug resistance 2016-2021. Geneva: World Health Organization; 2016.

5. Phillips AN, Stover J, Cambiano V, et al. Impact of HIV drug resistance on HIV/AIDS-associated mortality, new infections, and antiretroviral therapy program costs in sub-Saharan Africa. J Infect Dis. 2017;215(9):1362-5.

6. Boender TS, Hoenderboom BM, Sigaloff KC, Hamers RL, Wellington M, Shamu T, Siwale M, Labib Maksimos EE, Nankya I, Kityo CM, et al. Clin Infect Dis. 2015;61(11):1749-58 (Epub 2015 Aug 3).

7. Boender TS, Hoenderboom BM, Sigaloff KC, et al. Pretreatment HIV drug resistance increases regimen switches in sub-Saharan Africa. Clin Infect Dis. 2015;61:1749-58.

8. Petersen ML, Tran L, Geng EH, et al. Delayed switch of antiretroviral therapy after virologic failure associated with elevated mortality among HIV-infected adults in Africa. AIDS. 2014:28:2097-107.

9. Sigaloff KC, Hamers RL, Wallis CL, et al. PharmAccess African Studies to Evaluate Resistance (PASER). Unnecessary antiretroviral treatment switches and accumulation of HIV resistance mutations; two arguments for viral load monitoring in Africa. J Acquir Immune Defic Syndr. 2011;58:23-31.

10. De Beaudrap P, Thiam M, Diouf A, et al. Risk of virological failure and drug resistance during first- and second-line antiretroviral therapy in a 10-year cohort in Senegal: results from the ANRS 1215 cohort. J Acquir Immune Defic Syndr. 2013;62:381-7.

11. Hamers RL, Sigaloff KCE, Kityo C, Mugyenyi P, de Wit TFR. Emerging HIV-1 drug resistance after roll-out of antiretroviral therapy in sub-Saharan Africa. Curr Opin HIV AIDS. 2013;8(1):19-26.

12. Bulteel N, Bansi-Matharu L, Churchill D, the UK Collaborative HIV Cohort (CHIC) Study Group, and the UK HIV Drug Resistance Database (UK HDRD) Study Group, et al. The emergence of drug resistant HIV variants at virological failure of HAART combinations containing efavirenz, tenofovir and lamivudine or emtricitabine within the UK Collaborative HIV Cohort. J Infect. 2014;68:77-84.

13. Ceccarelli $L$, et al. Characterization of drug resistance mutations in naive and ART-treated patients infected with HIV-1 in Yaounde, Cameroon. J Med Virol. 2012;84(721):727. https://doi.org/10.1002/jmv.23244.

14. Margot NA, Enejosa J, Cheng AK, Miller MD, McColl DJ, the Study 934 Team. Development of HIV-1 drug resistance through 144 weeks in antiretroviral-naïve subjects on emtricitabine, tenofovir disoproxil fumarate, and efavirenz compared with lamivudine/zidovudine and efavirenz in study GS-01-934. J Acquir Immune Defic Syndr. 2009:52:209-21.

15. Gregson J, Tang M, Ndembi N, et al. Global epidemiology of drug resistance after failure of WHO recommended first-line regimens for adult HIV-1 infection: a multicentre retrospective cohort study. Lancet Infect Dis. 2016;16:565-75.

16. Boyd MA, Moore CL, Molina JM, et al. SECOND-LINE study group Baseline HIV-1 resistance, virological outcomes, and emergent resistance in the SECOND-LINE trial: an exploratory analysis. Lancet HIV. 2015;2:e42-51.

17. Rossouw TM, Feucht UD, Melikian G, Van Dyk G, Thomas W, Du Plessis NM, Avenant T. Factors associated with the development of drug resistance mutations in HIV-1 infected children failing protease inhibitor-based antiretroviral therapy in South Africa. PLoS ONE. 2015;10(7):e0133452. https://doi.org/10.1371/journal.pone.0133452.

18. WHO guidelines in 2003: Scaling up antiretroviral therapy in resourcelimited settings: Treatment guidelines for a public health approach; 2003.

19. WHO guidelines in 2006: Antiretroviral therapy for HIV infection in adults and adolescents; 2006. 
20. WHO guidelines in 2010: World Health Organization. Antiretroviral therapy for HIV infection in adults and adolescents. Recommendations for a public health approach: 2010 revision; 2010.

21. World Health Organization. Consolidated guidelines on the use of antiretroviral drugs for treating and preventing HIV infection: recommendations for a public health approach. http://apps.who.int/iris/bitstream/10665 /85321/1/9789241505727_eng.pdf. Accessed 11 Nov 2017.

22. https://www.who.int/hiv/pub/guidelines/arv2013/art/WHO_CG_table 7.15.pdf. Accessed 22 June 2018

23. STATA version 11.0 (College Station, TX, USA)College Station, TX, USA.

24. Khienprasit N, Chaiwarith R, Sirisanthana T, Supparatpinyo K. Incidence and risk factors of antiretroviral treatment failure in treatment-naïve HIVinfected patients at Chiang Mai University Hospital, Thailand. AIDS Res Ther. 2011:8(1):42. https://doi.org/10.1186/1742-6405-8-42.

25. Palmer DB. The effect of age on thymic function. Front Immunol. 2013:4:316. https://doi.org/10.3389/fimmu.2013.00316.

26. Ma D, Wei Y, Liu F. Regulatory mechanisms of thymus and T cell development. Dev Comp Immunol. 2013;39:91-102. https://doi.org/10.1016/j. dci.2011.12.013.

27. Mpondo BCT. HIV infection in the elderly: arising challenges. J Aging Res. 2016;2016:2404857. https://doi.org/10.1155/2016/2404857.

28. Burgess MJ, Zeuli JD, Kasten MJ. Management of HIV/AIDS in older patients- drug/drug interactions and adherence to antiretroviral therapy. HIV/AIDS (Auckland, NZ). 2015;7:251-64. https://doi.org/10.2147/HIV. S39655.

29. Chary Aarthi, Nguyen Nancy N, Maiton Kimberly, Holodniy Mark. A review of drug-drug interactions in older HIV-infected patients. Expert Rev Clin Pharmacol. 2017;10(12):1329-52. https://doi.org/10.1080/17512 433.2017.1377610.

30. Kabugo C, Bahendeka S, Mwebaze R, Malamba S, Katuntu D, Downing R, Mermin J, Weidle PJ. Long-term experience providing antiretroviral drugs in a fee-for-service HIV clinic in Uganda. J Acquir Immune Defic Syndr. 2005;38:578-83. https://doi.org/10.1097/01.qai.0000134742.26338.2f.

31. Kiecolt-Glaser JK, Wilson SJ. Lovesick: how couples' relationships influence health. Annu Rev Clin Psychol. 2017;13:421-43.

32. Katz IT, Ryu AE, Onuegbu AG, Psaros C, Weiser SD, Bangsberg DR, Tsai AC. Impact of HIV-related stigma on HIV treatment adherence: systematic review, meta-synthesis, and conceptual model. J Int AIDS Soc. 2013;16:18640.

33. Kelly J, Amirkhanian Y, Yakovlev A, et al. Stigma reduces and social support increases engagement in medical care among persons with HIV infection in St Petersburg, Russia. J Int AIDS Soc. 2014;17(4 Suppl 3):19618.

34. Li MJ, Murray JK, Suwanteerangkul J, Wiwatanadate P. Stigma, social support, and treatment adherence among HIV-positive patients in Chiang Mai, Thailand. AIDS Educ Prev. 2014;26(5):471-83.

35. Ironson G, O'Cleirigh C, Kumar M, et al. Psychosocial and neurohormonal predictors of HIV disease progression (CD4 cells and viral load): a 4 year prospective study. AIDS Behav. 2015;19(8):1388-97.

36. Takada S, Weiser SD, Kumbakumba E, et al. The dynamic relationship between social support and HIV-related stigma in rural Uganda. Ann Behav Med. 2014;48(1):26-37.

37. Molloy GJ, Hamer M, Randall G, Chida Y. Marital status and cardiac rehabilitation attendance: a meta-analysis. Eur J Cardiovasc Prev Rehabil. 2008;15(5):557-61.

38. Uzochukwu BS, et al. Determinants of non-adherence to subsidized anti-retroviral treatment in southeast Nigeria. Health Policy Plan. 2009;24(3):189-96. https://doi.org/10.1093/heapol/czp006.
39. Obirikorang C, Selleh PK, Abledu JK, Fofie CO. Predictors of adherence to antiretroviral therapy among HIV/AIDS patients in the upper west region of ghana. 2013;2013:873939. https://doi.org/10.1155/2013/873939.

40. Rachlis B, Cole DC, van Lettow $M$, et al. Follow-up visit patterns in an antiretroviral therapy (ART) programme in Zomba, Malawi. PLoS ONE. 2014;9(7):e101875. https://doi.org/10.1371/journal.pone.0101875.

41. Palumbo R. Discussing the effects of poor health literacy on patients facing HIV: a narrative literature review. Int J Health Policy Manag. 2015:4(7):417-30. https://doi.org/10.15171/ijhpm.2015.95.

42. Johannessen A, Naman E, Kivuyo SL, et al. Virological efficacy and emergence of drug resistance in adults on antiretroviral treatment in rural Tanzania. BMC Infect Dis. 2009;9:108. https://doi. org/10.1186/1471-2334-9-108.

43. Laurent C, Gueye NFN, Ndour CT, et al. Long-term benefits of highly active antiretroviral therapy in Senegalese HIV-1-infected adults. J Acquir Immune Defic Syndr. 2005;38(1):14-7. https://doi.org/10.1097/00126334200501010-00003.

44. Seyler C, Adjé-Touré C, Messou E, et al. Impact of genotypic drug resistance mutations on clinical and immunological outcomes in HIV-infected adults on HAART in West Africa. AIDS. 2007;21(9):1157-64.

45. Uy J, Armon C, Buchacz K, Wood K, Brooks JT, Kb JTB, Wendrow A. Initiation of HAART at higher CD4 cell counts is associated with a lower frequency of antiretroviral drug resistance mutations at virologic failure. J Acquir Immune Defic Syndr. 2009;51(4):450-3. https://doi.org/10.1097/ qai.0b013e3181acb630.

46. Jose S, Quinn K, Dunn D, et al. Virological failure and development of new resistance mutations according to CD4 count at combination antiretroviral therapy initiation. HIV Med. 2015;17(5):368-72.

47. Palella FJJ, Armon C, Chmiel JS, et al. CD4 cell count at initiation of ART, long-term likelihood of achieving CD4 $>750$ cells $/ \mathrm{mm}^{3}$ and mortality risk. J Antimicrob Chemother. 2016;71(9):2654-62.

48. Puttamaswin S, Ubolyam S, Trichavaroj R, Butterworth O, Turk E, McCullough C, Chomont N, de Souza M, Robb ML, Phanuphak N, Ananworanich J for the RV254/SEARCH010 Study Group. Viral blips after treatment initiation during acute HIV infection. Clinical Infectious Diseases. 2019 Sep 24

49. Li JZ, Paredes R, Ribaudo HJ, et al. Low-frequency HIV-1 drug resistance mutations and risk of NNRTI-based antiretroviral treatment failure: a systematic review and pooled analysis. JAMA. 2011;305(13):1327-35.

50. O'Connor JL, Gardner EM, Mannheimer SB, the INSIGHT SMART Study Group, et al. Factors associated with adherence amongst 5295 people receiving antiretroviral therapy as part of an international trial. J Infect Dis. 2013;208:40-9.

51. Bangsberg DR, Charlebois ED, Grant RM, et al. High levels of adherence do not prevent accumulation of HIV drug resistance mutations. AIDS. 2003; 17:1925-32

52. Weaver ERN, Pane M, Wandra T, Windiyaningsih C, Herlina Samaan G. Factors that influence adherence to antiretroviral treatment in an urban population, Jakarta, Indonesia. PLoS ONE. 2014;9(9):e107543. https://doi. org/10.1371/journal.pone.010754.

\section{Publisher's Note}

Springer Nature remains neutral with regard to jurisdictional claims in published maps and institutional affiliations. 